\title{
Robots and Archwire Bending, a Better Solution? Literature Review
}

\author{
Assim Anas Assim Alsalam, Rashid Mohammad Iqbal and Huda \\ Abutayyem* \\ Department of Orthodontics, RAKCODS, UAE \\ *Corresponding Author: Huda Abutayyem, Department of Orthodontics, \\ RAKCODS, UAE.
}

Received: August 24, 2020

Published: October 28, 2020

(C) All rights are reserved by Huda

Abutayyem., et al.

\begin{abstract}
Background: orthodontic appliance is the basis of the orthodontic treatment and making it more accurate and efficient would improve the general orthodontic treatment and change the standards of oral health.

Aims: The point of this research was to differentiate between the conventional wire bending in fixed orthodontic appliances and the automated robot made wire. Additionally, to see if robot wire bending is dominating and has favored results over ordinary wire bending.

Materials and Methods: articles from January 2010 to June 2020 were revised and searched. Databases, for example, MEDLINE through Ovid, Cochrane Library, LILACS, Web of science and Embase were utilized due to the availability of the medical articles which were useful for the research.

Results: in this study 7 papers were included and it was found that the result of using a robot to bend the archwire in the process of making a fixed appliance will increase the treatment accuracy, efficacy and efficiency, also decreasing the treatment time and patient discomfort thus improving the orthodontic treatment in general.

Conclusion: orthodontics treatment which utilizes a machine or a robot to twist the archwire that is used in fixed orthodontics device will have a significantly improved result with incredibly less treatment time when compared to the normal methods.
\end{abstract}

Keywords: Archwire; Robots; Orthodontic Treatment

\section{Introduction}

A robot is a machine particularly one programmable by a PC equipped for completing an unpredictable arrangement of activities naturally [1]. These days, robots are utilized in modern field, fabricating measure, clinical fields, and military purposes. Robots are being created an developed to serve in different aspects of the medical field [2].

Different employments of robots are: Minimally obtrusive medical procedure, surgical operations that requires precision, amplification which gives better vision to the specialist, shorter clinic remains for recuperation. Also, Dentistry has seen colossal im- provements and movements from the standard techniques to the modernized world that has enlarged the degree of dental treatment and frameworks [3]. It can understand the accompanying capacities: the assembling of partial or complete dentures, dental implant placements, and the twisting of orthodontic archwire. The technique of the work and the experience between the technician and the specialist is incorporated in the framework of the product [4].

Advancements in three-dimensional imaging and assembling measures have made the customization of orthodontic apparatuses to improve treatment effectiveness conceivable. Advances in innovation have yielded two patient-explicit items that use computers 
to make an intelligent treatment plan, and afterward make a customized appliance, such as: the Insignia ${ }^{\circ}$ system (Ormco Corporation, Orange, CA, USA) and Suresmile archwires (OraMetrix, Inc., Richardson, TX, USA) [5].

\section{Review of the Literature}

Robots have numerous applications in the orthodontic field and coming up next are the most well-known procedures that utilize the advantages of the robots.

\section{Insignia}

The Insignia structure outfits clinicians with programming that encourages them plan and draw the last impediment, and a short time later segments and archwires are made to move teeth to the ideal outcome (Figure 1). The association offers quiet explicit brackets, and custom archwires. The custom archwires are made by a printing robot that utilizes the framework gave to follow and twist the wire appropriately (Figure 2), the accuracy of the robot is very high and the margin of error is very small [5].

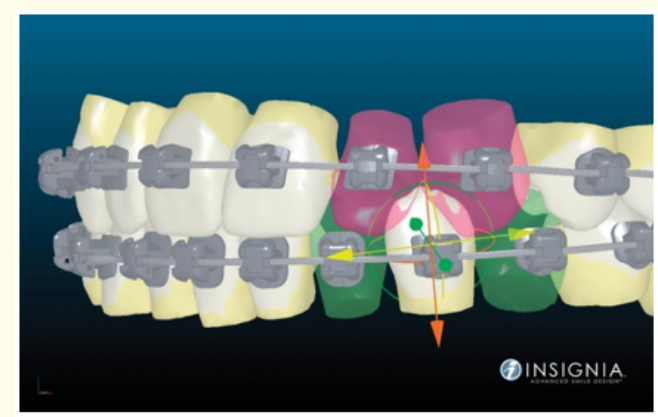

Figure 1: Insignia system software.

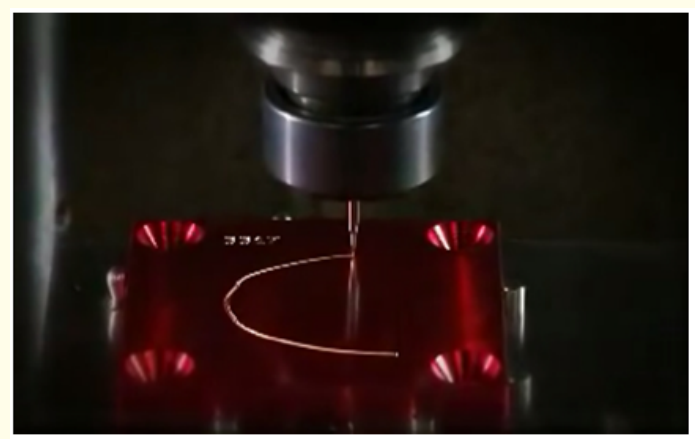

Figure 2: Wire fabrication robot.
One of the clients of insignia in 2009 recommended the framework due to its ability of designing a very individual treatment, also it gives a window to work with the end result in mind. A clinical report has been published on the rule features and the clinical central focuses of the Insignia framework. They demonstrated the treatment effectiveness of the framework when treating a male, 16 years- old who had a Class II malocclusion for 17 months and they did not need to rebond the sections or curve the archwires. The results of 35 cases treated with insignia were compared to the results of 11 cases treated in a traditional manner by means of the treatment time and outcomes [5].

The scores of the insignia treated cases were very close to the perfect scores according to the American Board of Orthodontics (ABO). Also, the treatment time was significantly shorter when comparing insignia to other techniques (14.23 months versus 22.91 months) [5].

\section{Suresmile}

The procedure starts with the orthodontists uses digital images of a patient's mouth and teeth using either a white light scanner or cone beam computed tomography (CBCT). Afterwards the technician adjusts the teeth to ideal position. The information is then sent to a computer were little adjustments take place. The dentist inters the data that has the location and the tension for the brackets and the wires to the system and sends it to suresmile head office. Now the use of the robots start, the archwire is held by two mechanical grasping pliers which beds the wire into the desirable shape [6].

The twisting device is known as SureSmile archwire bending robot. The twisting device includes a robot mounted to a base. First grasping apparatus has a structure for holding the archwire and is either be fixed with respect to the base or may be incorporated into a movable arm (Figure 3 ). The second holding device is mounted as far as possible of a movable six-hub robot arm having a proximal part additionally mounted to the base and a distal end that can move with respect to the fixed grasping apparatus around three transitional and three rotational axes. Ideally, the holding instruments join constrain sensors which are utilized to decide overbends expected to get the ideal last shape of the archwire and may likewise incorporate a resistive heating system in which current flows through the wire while the wire is held in a bent condition to heat the wire and thereby retain the bent shape of the wire [6]. 
93

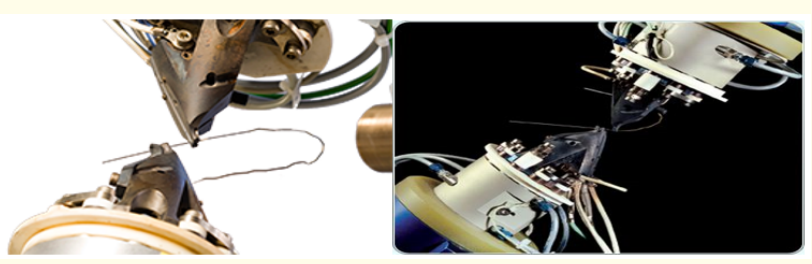

Figure 3: Suresmile archwire bending robot.

\section{LAMDA system}

LAMDA system or a lingual archwire manufacturing and design aid is a system for rapid and exact bending of the archwire as shown in figure 4 . The system uses a robot that can bend the archwire in two planes which restricts the applications of the system [6].

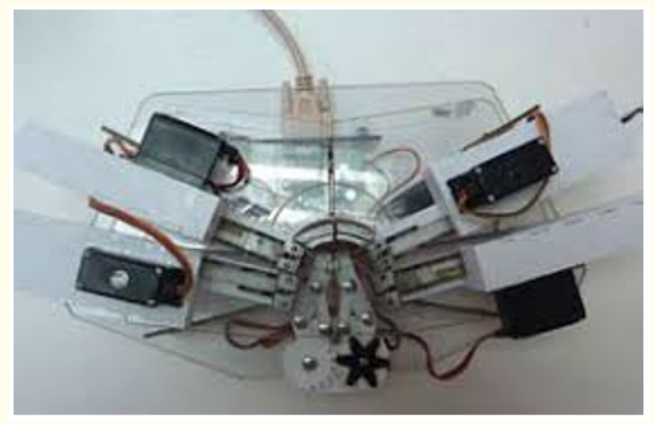

Figure 4: LAMDA system.

\section{MOTOMAN UP6}

A different type of a robot used in orthodontic archwire bending that is based on MOTOMAN UP6, it is composed of a computer and a twisting devices for the archwire (Figure 5) [7].



Figure 5: Archwire bending robot based on MOTOMAN UP6.

\section{Cartesian type archwire bending robot}

This system of archwire bending uses a robot that has multiple components as shown in (Figure 6). The bending procedure is examined and the structure of the archwire is designed with the included software. Experimentations are being performed using the Cartesian framework and results are being compared. Figure 7 shows an example of an archwire that is bent using the Cartesian framework [8].



Figure 6: Cartesian type archwire bending robot.

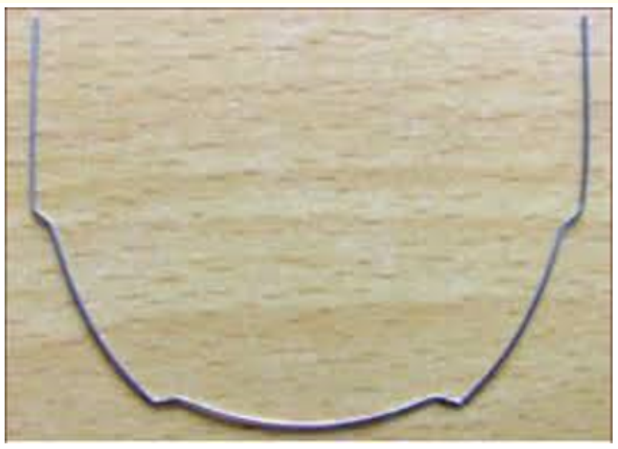

Figure 7

The difficulties of future application of robotics in dentistry

- Design complexity: The complexity of the oral cavity and the physical characteristics of the archwire material give a challenge to the robot to fulfill the requirements needed for the perfect orthodontic treatment [6].

- Availability of research: New researches needed about the orthodontic archwire physical properties to enhance the work precision of the archwire bending robots [6].

- Necessary developments for the application of robots: Progression has been made in the exploration of the utilization of robot in orthodontics, yet it isn't done. To fulfill the requirement of the market and to get the benefits of the work of robots some studies have to be made on one of the following 
- $\quad$ Archwire structure: Robots are meant to be flexible reliable and accurate, but all of that is restricted by the space of the oral cavity that's why developments have to be made to reduce the degree of freedom of the robots.

- Controls for good bending: Research has to focus on the spring- back and bending algorithm for the archwire bending robots.

- Human and computer interaction: Human and computer participation is the key element for the advancement and the future research has to focus on 3D virtual showcase of the orthodontic appliances, a virtual expectation of the treatment. It is hard for the robot to perceive working condition with the obstacles of the structures of the oral cavity which is why there is always a need for the human part in the treatment [6].

The point of this research was to differentiate between the conventional wire bending in fixed orthodontic appliances and the automated robot made wire. Additionally, to see if robot wire bending is dominating and has favored results over ordinary wire bending.

\section{Materials and Methods}

This study is a literature review based study. The inclusion criteria, all the studies that were conducted from 2010 up to august 2020. The databases which were used to search include, MEDLINE via Ovid, Embase, Web of science, LILACS, Cochrane Library The exclusion criteria were articles in foreign languages other than English, experimental studies with animals and short communications.

\section{Data collection procedure}

The databases were searched using the keywords: robots in dentistry, orthodontics, archwire bending, robotic use in orthodontics. Articles for possible inclusion were identified and collected.

\section{Ethical consideration}

Ethical approval was obtained from RAK Research Ethics Committee and favorable ethical opinion was obtained from The Ministry of Health and Prevention Research Ethics Committee; under reference number (REC-21-R-2018-UG-D).

\section{Results}

Study process: the databases (MEDLINE via Ovid, Embase, Web of science, LILACS and Cochrane Library) were searched; an absolute number of 75 articles were identified for a potential inclusion. Only 7 articles were included in the research according to inclusion criteria and 6 articles were excluded according to the exclusion criteria. As shown in the flow diagram.

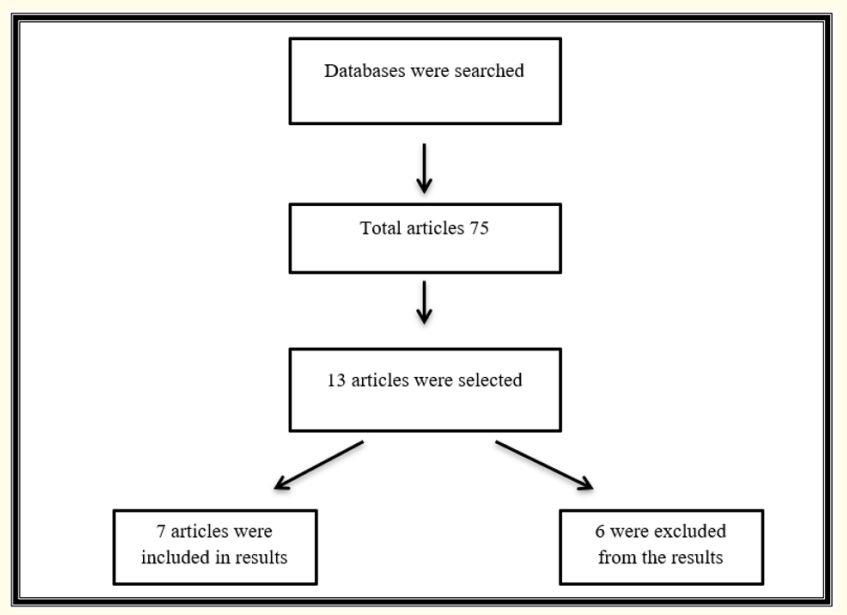

Figure 8: Flow diagram of the method of data collection.

\begin{tabular}{|c|c|c|c|c|c|}
\hline & Author & Title & Year & Journal & Result \\
\hline 1 & Jin-Gang Jiang, et al. & $\begin{array}{c}\text { A Review on Robot in Prosth- } \\
\text { odontics and Orthodontics }\end{array}$ & 2014 & $\begin{array}{c}\text { Advances in Mechanical } \\
\text { Engineering }\end{array}$ & $\begin{array}{c}\text { Improving reproducibility, effi- } \\
\text { ciency, and quality of orthodontic } \\
\text { treatment }\end{array}$ \\
\hline 2 & $\begin{array}{c}\text { Ahmad S. Kh and } \\
\text { Drogomyretska }\end{array}$ & $\begin{array}{c}\text { A Glance about the Applica- } \\
\text { tions of Robot in Orthodon- } \\
\text { tics. }\end{array}$ & 2016 & $\begin{array}{c}\text { International Journal of } \\
\text { Innovation and Scientific } \\
\text { Research }\end{array}$ & $\begin{array}{c}\text { Improving reproducibility, effi- } \\
\text { ciency, and quality of orthodontic } \\
\text { treatment }\end{array}$ \\
\hline Aldrees, A. & $\begin{array}{c}\text { Do customized orthodontic } \\
\text { appliances and vibration de- } \\
\text { vices provide more efficient } \\
\text { treatment than conventional } \\
\text { methods? }\end{array}$ & 2016 & $\begin{array}{c}\text { The Korean Journal of } \\
\text { Orthodontics }\end{array}$ & $\begin{array}{c}\text { Reduction in the total treatment } \\
\text { time with the use of robots in arch- } \\
\text { wire bending }\end{array}$ \\
\hline
\end{tabular}

Citation: Huda Abutayyem., et al. "Robots and Archwire Bending, a Better Solution? Literature Review”. Acta Scientific Dental Sciences 4.11 (2020): $91-97$. 


\begin{tabular}{|c|c|c|c|c|c|}
\hline 4 & Alford. T, et al. & $\begin{array}{l}\text { Clinical outcomes for } \\
\text { patients finished with the } \\
\text { SureSmile }{ }^{\mathrm{TM}} \text { method com- } \\
\text { pared with conventional } \\
\text { fixed orthodontic therapy. }\end{array}$ & 2011 & The Angle Orthodontist & $\begin{array}{l}\text { Suresmile } ® \text { was associated with } \\
\text { a shorter treatment time, and } \\
\text { resulted in a lower ABO cast- } \\
\text { radiograph evaluation score }\end{array}$ \\
\hline 5 & Kumar, P & $\begin{array}{l}\text { Future Advances in Robotic } \\
\text { Dentistry. }\end{array}$ & 2017 & $\begin{array}{c}\text { Journal of Dental Health, } \\
\text { Oral Disorders and } \\
\text { Therapy }\end{array}$ & $\begin{array}{l}\text { improved and precise treatment } \\
\text { with good quality of work in a less } \\
\text { amount of time }\end{array}$ \\
\hline 7 & Gilbert. A & $\begin{array}{l}\text { An In-Office Wire-Bending } \\
\text { Robot for Lingual Orthodon- } \\
\text { tics }\end{array}$ & 2011 & $\begin{array}{l}\text { journal of clinical ortho- } \\
\text { dontics }\end{array}$ & $\begin{array}{l}\text { A } 16 \text { th orthodontist performed a } \\
\text { blind evaluation of the } 30 \text { archwires, } \\
\text { assigning a score between zero and } \\
10 \text { to each wire based on how well it } \\
\text { adapted to the cast. The mean score } \\
\text { for the } 15 \text { manually bent archwires } \\
\text { was } 6.9 \text {; the mean score for the } 15 \\
\text { archwires designed and manufac- } \\
\text { tured with the LAMDA system was } \\
9.0\end{array}$ \\
\hline
\end{tabular}

Table 1: Included articles.

\begin{tabular}{|c|c|c|c|c|c|}
\hline & Author & Title & Year & Journal & Reason of exclusion \\
\hline 2 & Gilbert, H. and Webster III, R & $\begin{array}{c}\text { Rapid, Reliable Shape } \\
\text { Setting of Superelastic } \\
\text { Nitinol for Prototyping } \\
\text { Robots. }\end{array}$ & 2016 & $\begin{array}{l}\text { IEEE Robotics and Automation } \\
\text { Letters }\end{array}$ & $\begin{array}{l}\text { Not focusing on the } \\
\text { same idea }\end{array}$ \\
\hline 3 & Rigelsford, J & $\begin{array}{l}\text { Robotic bending of } \\
\text { orthodontic archwires }\end{array}$ & 2004 & $\begin{array}{c}\text { Industrial Robot: An International } \\
\text { Journal }\end{array}$ & Before 2010 \\
\hline 4 & Jha Kukreja, B., et al. & $\begin{array}{l}\text { Robotic dentistry- the } \\
\text { future is at the horizon }\end{array}$ & 2012 & $\begin{array}{l}\text { Journal of pharmaceutical and } \\
\text { biomedical sciences }\end{array}$ & $\begin{array}{l}\text { Not focusing on the } \\
\text { same idea }\end{array}$ \\
\hline 6 & Mah, J. and Sachdeva, R & $\begin{array}{l}\text { Computer-assisted } \\
\text { orthodontic treatment: } \\
\text { The SureSmile process }\end{array}$ & 2001 & $\begin{array}{l}\text { American Journal of Orthodontics } \\
\text { and Dentofacial Orthopedics }\end{array}$ & Before 2010 \\
\hline
\end{tabular}

Table 2: Excluded articles. 


\section{Discussion}

This research was chosen to compare between the results of conventional wire bending in fixed orthodontic appliances and the mechanical robot made wire. To check if robot wire bending is predominant and has preferred outcomes over customary wire bending. In orthodontics there has always an attempt to improve efficiency and efficacy of appliances. Since its beginning, numerous modalities have been changed and improved to expand quality to the furthest extent.

Articles from 2010 onwards were used for the research. Databases such as MEDLINE via Ovid- Web of science- Embase- Cochrane Library- LILACS were used as they contain all the medical articles which was very helpful for the research.

This study found that the result of using a robot to bend the archwire in the process of making a fixed appliance will increase the treatment accuracy, efficacy and efficiency, This result was supported by a number of recent studies that were conducted to evaluate the use of robots or machines to bend the archwire that is used in the orthodontic fixed appliances to the desired shape and reached the result that the use of a robot when compared to the conventional archwire manufacturing can improve the reproducibility, efficiency and the quality itself of the orthodontic treatment [4,6-8]. Another study has found that the archwire bending robot had a significantly higher mean grades in accuracy when compared to a skilled professional orthodontic practitioners that were given the same tasks of the robot. The specialists got a mean score of 6.9 and it was compared to the mean score of a robot which was a 9 in case of accuracy [9].

Also in this study it was found that the use of a robot in the archwire bending process is a rapid and accurate design that can enhance the treatment time and the patient comfort thus enhances the outcome, this makes the use of robots to bend the archwire a very good option if not superior to the conventional methods in selecting the treatment options, this was supported by a number of studies [4-7].

Regarding treatment time, this study has found that the treatment time is improved significantly when the process of bending the archwire has involved the use of specialized robots but was not supported by a study that suggested that the use of a robot to bend the archwire can decrease the treatment time but not for all the cases, only the simple ones because the study was not performed on a severe malocclusion cases only mild cases [10-21].

\section{Conclusion}

All in all, this research demonstrated that orthodontic treatment which utilizes a robot or a machine to twist the archwire that is utilized in fixed orthodontic appliance will have a vastly improved result with a strikingly less treatment time in comparison to the regular technique that utilizes an expert rather than a machine, with expanded accuracy and diminished patient disscomfort. The most widely recognized procedures that utilize the robots in archwire twisting are insignia and suresmile which have demonstrated their prevalence upon different strategies.

\section{Bibliography}

1. Definition of 'robot'. Oxford English Dictionary (2016).

2. Staples P. "Robots Used in Everyday Life”. Sciencing (2018).

3. B Divya Bhat., et al. "Robotics in dentistry: Fiction or reality". Journal of Dental Research and Review 4 (2017): 67-68.

4. Jin-Gang Jiang YDZ., et al. "A Review on Robot in Prosthodontics and Orthodontics". Advances in Mechanical Engineering 7 (2014).

5. Aldrees A. "Do customized orthodontic appliances and vibration devices provide more efficient treatment than conventional methods?". The Korean Journal of Orthodontics 46.3 (2016): 180.

6. Ahmad S Kh., et al. "A Glance about the Applications of Robot in Orthodontics". International Journal of Innovation and Scientific Research 22.1 (2016): 178-182.

7. Kumar P. "Future Advances in Robotic Dentistry". Journal of Dental Health, Oral Disorders and Therapy 7.3 (2017).

8. Jiang J., et al. "Recent Advances in Orthodontic Archwire Bending Robot System". Recent Patents on Mechanical Engineering 9.2 (2016): 125-135.

9. Gilbert H and Webster III R. "Rapid, Reliable Shape Setting of Superelastic Nitinol for Prototyping Robots". IEEE Robotics and Automation Letters 1.1 (2016): 98-105.

10. Alford T., et al. "Clinical outcomes for patients finished with the SureSmile ${ }^{\mathrm{TM}}$ method compared with conventional fixed orthodontic therapy". The Angle Orthodontist 81.3 (2011): 383-388.

11. Bhatia G. "Top robotic applications in medicine" (2018).

12. Khursheed R. "Robots and robotics used in orthodontics" (2015). 
13. Robotic Braces. "The Science Channel”. Brink (2009).

14. Crawford M. "Top 6 Robotic Applications in Medicine” (2016).

15. Gilbert A. "An In-Office Wire-Bending Robot for Lingual Orthodontics". Journal of Clinical Orthodontics 45.4 (2017): 230.

16. Demas. "Bending Wires: A Procedure that should be Accurately Done | Demas" (2017).

17. Rigelsford J. "Robotic bending of orthodontic archwires". Industrial Robot: An International Journal 31.6 (2004).

18. Jha Kukreja B., et al. "Robotic dentistry- the future is at the horizon". Journal of Pharmaceutical and Biomedical Sciences 16.1 (2012).

19. Zhang Y and Jiang J. "Analysis and Experimentation of the Robotic System for Archwire Bending". Applied Mechanics and Materials 121-126 (2011): 3805-3809.

20. Mah J and Sachdeva R. "Computer-assisted orthodontic treatment: The SureSmile process". American Journal of Orthodontics and Dentofacial Orthopedics 120.1 (2001): 85-87.

21. Orthodontic Associates. SureSmile® - Orthodontic Associates.

\section{Assets from publication with us}

- Prompt Acknowledgement after receiving the article

- Thorough Double blinded peer review

- Rapid Publication

- Issue of Publication Certificate

- High visibility of your Published work

Website: www.actascientific.com/

Submit Article: www.actascientific.com/submission.php

Email us: editor@actascientific.com

Contact us: +919182824667

Citation: Huda Abutayyem., et al. "Robots and Archwire Bending, a Better Solution? Literature Review". Acta Scientific Dental Sciences 4.11 (2020): $91-97$. 